\title{
Might salicylate exert benefits against childhood cancer?
}

\section{G Morgan ${ }^{1}$ and JI Johnsen ${ }^{2}$}

${ }^{1}$ Fellow of the Royal Institute for Public Health, National Health Service for Wales, Wales, UK

${ }^{2}$ Childhood Cancer Research Unit, Department of Woman and Child Health, Karolinska Institutet, Stockholm, Sweden

\begin{abstract}
Childhood cancers are a broad range of diseases. Research on the chemopreventive potential of non-steroidal anti-inflammatory drugs, such as aspirin (acetylsalicylate) has yet to be fully directed towards childhood cancers. A prima facie hypothesis on salicylate and childhood cancer would therefore be based on several factors. Firstly, salicylate inhibits the production of inflammatory prostaglandins, which have been shown to stimulate the growth of cancer cells. Secondly, salicylate inhibits the growth of cancer cells in pre-clinical models. Thirdly, salicylate is a natural component of fruits and vegetables so it is consumed within the diet. Further research, of which some possibilities are identified, is recommended.
\end{abstract}

Published: 19/01/2010

Received: 19/09/2009

ecancer 2010, 4:156 DOI: 10.3332/ecancer.2010.156

Copyright: (C) the authors; licensee ecancermedicalscience. This is an Open Access article distributed under the terms of the Creative Commons Attribution License (http://creativecommons.org/licenses/by/2.0), which permits unrestricted use, distribution, and reproduction in any medium, provided the original work is properly cited.

Competing Interests: The authors have declared that no competing interests exist.

Correspondence to G Morgan. Email: morgan@fforrdbeck.fsnet.co.uk 


\section{Introduction}

Aspirin, acetylsalicylate, belongs to a class of medicines known as non-steroidal anti-inflammatory drugs (NSAIDs). These medicines are widely used for the treatment and alleviation of pain, inflammation and fever. However, undesirable effects, such as gastrointestinal irritation and an increased risk of cardiovascular events, limit the use of these medicines [1].

In low doses of $75-150 \mathrm{mg} / \mathrm{d}$, aspirin is used to reduce the risk of cardiovascular disease [2]. There is also a growing evidencebase that aspirin and other NSAIDs might reduce the risk of developing a wide range of cancers [3]. Hypotheses underpinning this possible benefit are that NSAIDs might exert chemopreventive effects during the process of cancer development, so-called multistage carcinogenesis [4]. One contributory effect is believed to be due, at least part, to the inhibition of cyclo-oxygenase (COX) enzymes, leading to the reduced production of pro-inflammatory eicosanoids, like prostaglandins [4]. COX-1 is expressed constitutively whilst COX-2 is induced during carcinogenesis, leading to high levels of prostaglandin $E_{2}$ production that supports cancer growth. In addition, aspirin and other NSAID have also been shown to directly inhibit the growth of cancer cells through COX-2independent mechanisms and by inhibition of angiogenesis [4]. Furthermore, salicylate, which is the principle active metabolite of aspirin in humans, has been shown to induce programmed cell death, apoptosis, in several cancer cell lines [4].

Childhood cancers are a broad range of diseases that are rare everywhere in the world [5]. In so-called developed countries, however, childhood cancers are the commonest cause of disease-related deaths in childhood, carrying with them great emotional and economic cost [6]. The descriptive epidemiology of childhood cancer also varies in accuracy. In countries where registration of childhood cancer cases is almost complete, the epidemiology of childhood cancer shows little or no increase in incidence of new cases per annum [7]. By contrast, in some countries, for example some Eastern European countries [8] and India [9], registration is poor and compromises research on trend analysis and disease aetiology. In low-income countries, it has been suggested that hospital-based registries could be developed [10].

Although there is considerable interest and active research on the chemopreventive potential of NSAIDs, this has yet to be directed towards childhood cancers to the same extent as adult malignancies. In this paper, hypotheses are presented for the first time in the expanded form that salicylate might exert benefits against childhood cancer. These hypotheses build on previous work [11] and possible future lines of research are identified. To offer a broader context, some aspects of childhood cancer aetiology are initially considered. Outside of the scope of this paper, however, is the proposal and broader debate that salicylate might be reclassified as vitamin $S$ [12].

\section{Aetiological aspects of childhood cancer}

With the exception of retinoblastoma (RB), where more than $40 \%$ of cases are due to an inherited mutation in the RB tumour suppressor gene [13], as well as in limited cases of Wilms tumour, Hodgkin's lymphoma and neuroblastoma, there is no clear evidence for a familial predisposition to childhood cancers [14-16]. This would in turn suggest a prominent role of modifiable risk factors in the aetiology of childhood cancer.

One such risk factor might be the exposure to infections. There is a hypothesis for an infectious aetiology for acute lymphoblastic leukaemia (ALL) but not for acute nonlymphoblastic leukaemia (AnLL) or for solid tumours such as those of the central nervous system (CNS) and neuroblastoma [17]. More generally, it is known that certain infections can predispose to cancer [18], such as human papillomavirus and the hepatitis virus. Vaccination programmes against these viruses are helpful to reduce the risk of cervical and liver cancer, respectively. Perhaps aspirin may also influence the risk of viral-induced cancers such as those caused by the EpsteinBarr virus [19] and Cytomegalovirus [20] by inhibiting cell invasion and exerting anti-viral effects, respectively.

Whilst recognizing the complexity of childhood cancer as a group of diseases, coupled to the difficulties of differentiating association from causation, two further modifiable risk factors are briefly discussed.

\section{Maternal exposure to risk factors}

Based on a study in the United Kingdom, socio-economic status does not appear to be a determinant of ALL in children [21]. This is potentially important since socio-economic status may be predictive of maternal lifestyle. Although much has been documented with regard to maternal diet, smoking, alcohol consumption and recreational or prescription drug use during pregnancy, there is no consistent evidence to support a link with any of these factors and childhood leukaemia [22].

Maternal exposure to solvents could further be investigated for ALL but evidence to date is limited given that it is based on selfreported data [23]. As a more general point, the adverse health 
effects linked to maternal exposures include foetal death, birth defects, being small for gestational age, pre-term birth, clinically overt cognitive, neurologic and behavioural abnormalities, subtle neuropsychological deficits, childhood cancer, asthma, other respiratory diseases and acute poisoning [24].

So, there is a broader challenge of correlating exposure to outcome for child health [25]. Expert groups faced with evaluating epidemiological evidence of potential causal relationships repeatedly encounter problems in summarizing the available data.

\section{Vitamin influence on childhood cancer risk}

Folic acid, vitamin B, is used in several countries as part of commercially available supplements and fortified foods for disease prevention [26]. Supplementations of folic acid to pregnant women have a beneficial effect in reducing the risk for neural tube defects in the offspring. There is evidence suggesting that folic acid supplementation also may reduce the risk of certain childhood cancers. Folic acid fortification in a Canadian study was associated with a significant $60 \%$ reduced risk for neuroblastoma development, whereas the incidence of ALL and hepatoblastoma remained unchanged [27].

Another study reported that maternal use of folic acid, both preconception and peri-conception, reduced the risk of brain tumours in the offspring. This may suggest that perhaps folic acid supplementation might prevent the development of cancers in a site-specific manner [28]. Moreover, pre-conception use of maternal multivitamin supplements containing folic acid demonstrated protective effects for childhood leukaemia, paediatric brain tumours and neuroblastoma [29]. Partly in contrast, a study from Germany showed that maternal use of multivitamins, folate and iron supplements reduced the risk of non-Hodgkin's lymphoma and perhaps leukaemia, but not tumours of the CNS. This study also demonstrated an associated increased risk for neuroblastoma in the offspring [30].

It has further been suggested that vitamin $D$ has potential anticancer activity and vitamin $D$ status is sub-optimal in many children in North America [31]. There is also a hypothesis of an increased risk of $A L L$ following vitamin $K$ given to newborns [32]. These influences, although questions remain, highlight the possible role of dietary components in the aetiology of childhood cancer.

\section{Hypotheses that salicylate might protect against childhood cancer}

The evidence on the factors of childhood cancer is far from complete and there are risk-significant unresolved questions and gaps in knowledge. Given this, there is capacity for additional factors that influence childhood cancer risk to be put forward. It is on this basis that there is scope to suggest hypotheses that salicylate might help reduce the risk of childhood cancer.

Aspirin is now rarely used in children because of an association with a condition known as Reye's syndrome [33]. It has been suggested that the reduced use of the medicine in children could be a factor in increasing childhood asthma [34].

The rare use of aspirin in children, which per se may have negative consequences, focuses a prima facie hypothesis on salicylate and childhood cancer on two factors. Firstly, salicylate exerts apoptotic effects on a broad range of cancer cell lines and NSAIDs inhibit the development and progression on preclinical in vivo models of neuroblastoma and medulloblastoma [35-37].

Secondly, salicylate is a natural component of fruits and vegetables so it is consumed in the diet [38]. Salicylate plays an important role in protecting tissues from disease and damage through the induction of apoptosis and in the inflammatory resolution phase. It therefore follows that those fruits and vegetables grown in natural conditions where they are exposed to the environment and pathogenic challenge express the highest levels of salicylate in their tissues [38]. A related hypothesis is that humans are becoming increasingly salicylate deficient [39] due to changes in food production and consumption patterns [40].

There has been interest in the vegetarian diet and reduced cancer risk [41]. It would therefore appear that the pharmacological properties of salicylate from pharmaceutical or dietary sources have relevance to human health and disease. Evidence extending over several decades demonstrates that salicylate exerts a number of effects on prostaglandin pathways [42]. More recent evidence suggests that these effects appear to be dependent, at least in part, on the intra-cellular oxidative conditions [43]. Salicylate might also exert anti-inflammatory effects through non-COX mechanisms [44]. For example, there is evidence that salicylate exerts its anti-inflammatory action in part through inhibition of the extracellular signal-regulated kinase (ERK) pathway. This is potentially important given that tumour necrosis factor- $\alpha$ can induce the ERK pathway [45]. 
There is also evidence that certain metabolites of salicylate may inhibit COX-2-dependent prostaglandin $E_{2}$ formation at sites of inflammation [46]. Further research would appear to be warranted to clarify the anti-inflammatory pathways of salicylate and metabolites [47]. Recently, acetylation of COX-2 by lowdose aspirin was shown to redirect the catalytic activity of COX2 away from generating pro-inflammatory prostaglandins and thromboxanes towards the production of lipoxins. The COX-2 enzyme with this modification remains catalytically active [48]. In contrast to prostaglandin $E_{2}$, which has proven procarcinogenic effects, one of the major end products of acetylated COX-2 is lipoxins (15-epi-lipoxin $A_{4}$ ), which have anti-tumourigenic effects [49]. In addition, other lipid mediators such as resolvins and protectins, important in the resolution phase of inflammation, are also produced by COX-2 and lipoxygenase enzymes from the omega-3 fatty acids eicosapentanoic acid (EPA) and docohexanenoic acid (DHA), which could explain some of the anti-carcinogenic properties of these compounds [48,49]. It is possible that the ingestion of salicylate exerts multiple effects, directly as a parent compound and also with respect to the metabolites produced. Research on these effects in human health and disease might help to identify new therapeutic targets for cancer control, both in children and adults.

\section{Effects of NSAIDs on pre-clinical models of solid childhood tumours}

Several studies have shown that different NSAIDs inhibit the growth of some solid childhood cancer cells in vitro, notably neuroblastoma, medulloblastoma including primitive neuroectodermal tumours (PNET) osteosarcoma and rhabdomyosarcoma [35-37,50-58]. Furthermore, both the COX-2-specific NSAID celecoxib and the dual COX-1/COX-2 inhibitor diclofenac significantly inhibit neuroblastoma and medulloblastoma growth in animal models [35-37].

Moreover, prophylactic treatments with celecoxib inhibit or prevent the development of neuroblastoma xenografts in rodents [54]. Celecoxib also significantly enhanced the effects of common chemotherapeutic drugs used in the treatment of neuroblastoma and medulloblastoma [35-37]. Medulloblastoma, PNET and neuroblastoma primary tumours express high levels of COX-2 and microsomal prostaglandin $E$ synthase-1 (mPGES-1), the two enzymes responsible for converting arachidonic acid, a dietary fatty acid and precursor to eicosanoid synthesis, to prostaglandin $E_{2}$. Compared to nonmalignant nervous tissue, neuroblastoma, medulloblastoma and other childhood nervous tumours contain increased levels of arachidonic acid $[60,61]$.

The presence of high levels of COX-2 and mPGES-1 in these tumours may therefore generate a pathogenic environment for the increased production of pro-carcinogenic prostaglandins. It has also been shown that prostaglandin $E_{2}$ increases proliferation of medulloblastoma cells and patients with malignant brain tumours have significantly higher concentrations of prostaglandin $E_{2}$ in their tumours and plasma compared to patients with benign brain tumours or non-cancer control patients [59-61]. Moreover, the concentration of prostaglandin $E_{2}$ in plasma decreases following neurosurgical resection of both malignant and benign brain tumours [61].

Taken together, these results suggest that dietary salicylate might be beneficial in the prevention of at least a subset of childhood cancers.

\section{Salicylate prevention of first and subsequent childhood cancers?}

Whilst recognizing that there may be some risks with ingesting high-levels salicylate during pregnancy [62], women may be exposed in two broad ways, which confer benefit. As suggested previously, the first of these is through dietary sources. The second is that some women might take aspirin, and there is evidence that in some cases of pre-eclampsia, low-doses of the medicine might be beneficial and increase birth weight [63]. This is potentially important per se given that low birthweight has been associated with numerous health problems during life [64].

One possible line of future research is therefore to understand the levels and effects of maternal exposure to salicylate on the risk of childhood cancer. More generally, such research could also examine maternal exposure to salicylate and other aspects of childhood health.

Maternal salicylate would also be expected to be secreted through breast milk. The effect of breastfeeding on childhood cancer risk is uncertain and increasing breastfeeding from $50 \%$ to $100 \%$ in the population has been estimated to prevent perhaps $5 \%$ of cases of childhood acute leukaemia or lymphoma at most [65]. Another consideration is the evidence that childhood fruit consumption may have a long-term protective effect on cancer risk in adults. Further prospective studies, with individual measures of diet, are required to further elucidate these relations [66].

There is evidence of a sustained increased risk of second malignancy in those treated for primary cancer, especially those 
diagnosed in childhood [67]. A study of salicylate levels in childhood cancer patients might therefore be a valuable research avenue. Such studies might measure salicylate levels non-invasively using readily available bodily fluids, such as urine. Perhaps dietary salicylate, particularly high in fruits and vegetables grown under organic conditions, could help reduce the risk of second malignancy. This could be tested experimentally through randomized trials with the active intervention being exposure to salicylate through fruits and vegetables.

Furthermore, salicylate might be an endogenous protective agent against cancer. There is evidence that humans have the ability to synthesize salicylate [68]. Salicylate deficiency or impaired metabolic pathways leading to synthesis might therefore be a factor in childhood cancer risk. In rare cases, however, some individuals experience salicylate intolerance [69]. A study of cancer risk in intolerant individuals might also be a productive research line. If salicylate does confer protection then intolerant individuals might have an increased risk of cancer.

Furthermore, laboratory-based experiments would also be helpful to increase knowledge and understanding of the effects of salicylate on childhood cancer.

\section{Some contemporary issues in childhood cancer}

Research evidence suggests that the continuing needs of childhood-cancer survivors include the provision of information of the later effects of treatment and self-care [70]. With respect to self-care, this might include tailored exercise programmes given that reduced physical activity is often a feature of childhood cancer, during and after treatment [71].

Across the world, childhood-cancer survival rates are increasing, for example one study from Singapore suggests that approximately $60 \%$ of patients overall survive more than two years [72]. Social aspects of surviving childhood cancers, such as impact on relationships, possibly highlight the need for longer support services to be offered [73]. Such psychosocial support might also be delivered to family members of childhood-cancer survivors [74].
Efforts to improve the cosmetic aspects of childhood cancer treatment, for example following irradiation of facial tissues, are also being developed and include the grafting of adipose tissue into affected areas [75]. Quality-of-life considerations in childhood cancer are also important and may differ, depending on the specific pathology. For example, evidence suggests that survivors of leukaemia have better quality of life than those with brain tumours [76].

Efforts to minimize the deleterious effects of childhood cancer treatment are also progressing [77]. Further research on the long-term health sequelae of surviving childhood cancer also appears warranted. There is evidence that irradiation, whole body or abdominal, can lead to an increase risk in developing type-2 diabetes mellitus [78] and, in females, complications in pregnancy have been described [79]. Increased risk of several long-term chronic health conditions, such as musculoskeletal disease, has been also observed in survivors of neuroblastoma [80]. Growth-hormone deficiency problems have also been described in childhood-cancer patients receiving cranial radiotherapy [81].

The scope for research and development on childhood cancer is considerable. This ranges from basic scientists continuing to develop pre-clinical cancer models, for example as demonstrated by work on hepatoblastoma [82], through to emergency department staff [83] as they may have opportunities to identify disease. The value of childhood cancer treatment being delivered by multidisciplinary teams appears important [84], especially when there is a high degree of distress within the family [85].

\section{Closing remarks}

Many lines of contemporary research and development are active in the field of childhood cancer research. Given the extensive, although not conclusive, evidence base supporting a potential benefit of aspirin against cancer, studies on salicylate and childhood cancer risk appears worthwhile. Further research, of which several lines are identified in the paper, is recommended. 


\section{References}

1. Roumie CL, Choma NN, Kaltenbach L, Mitchel EF, Arbogast PG and Griffin MR (2009) Non-aspirin NSAIDS, cyclooxygenase 2 inhibitors and risk for cardiovascular events-stroke, acute myocardial infarction and death from coronary heart disease Pharmacoepidemiol Drug Saf 18 1053-63 PMID: 19637402 doi:10.1002/pds. 1820

2. Antithrombotic Trialists' Collaboration (2009) Aspirin in the primary and secondary prevention of vascular disease: collaborative meta-analysis of individual participant data from randomised trials Lancet 3731849-69 PMID: $\underline{19482214}$ doi:10.1016/S0140-6736(09)60503-1

3. (2009) International consensus statement on aspirin and NSAIDs for cancer prevention Lancet Oncol 10 501-7 PMID: 19410194 doi:10.1016/S1470-2045(09)70035-X

4. Elwood PC, Gallagher AM, Duthie GG, Mur LAJ and Morgan G (2009) Aspirin, salicylates and cancer Lancet 373 1301-9 PMID: 19328542 doi:10.1016/S0140-6736(09) $\underline{60243-9}$

5. Stiller CA (2004) Epidemiology and genetics of childhood cancer Oncogene $23 \quad 28$ 6429-44 PMID: 15322515 doi:10.1038/sj.onc. 1207717

6. Buka I, Koranteng S and Osornio Vargas AR (2007) Trends in childhood cancer incidence: review of environmental linkages Pediatr Clin North Am 541 177-203 PMID: $\underline{17306690}$ doi:10.1016/j.pcl.2006.11.010

7. Linabery AM and Ross JA (2008) Trends in childhood cancer incidence in the US (1992-2004) Cancer 1122 416-32 PMID: 18074355 doi:10.1002/cncr.23169

8. Gatta G, Zigon G, Capocaccia R et al (2009) Survival of European children and young adults with cancer diagnosed 1995-2002 Eur J Cancer 456 992-1005 PMID 19231160 doi:10.1016/j.ejca.2008.11.042

9. Satyanarayana $L$ and Asthana S (2007) Childhood cancer risk trends in India (1982-2000) Indian Pediatr 4412 93941 PMID: 18175853

10. Howard SC, Metzger ML, Willimas JA, Quintana Y, Pui CH, Robison LL and Ribeiro RC (2008) Childhood cancer epidemiology in low income countries Cancer $1123461-$ 72 PMID: 18072274 doi:10.1002/cncr.23205

11. Morgan G (2005) Could vitamin S (salicylate) protect against childhood cancer? Med Hypotheses 643661 PMID: 15617884 doi:10.1016/j.mehy.2004.10.001

12. Morgan G (2004) An aspirin a day New Scientist 7 36-9

13. Dyer MA and Bremner $R$ (2005) The search for the retinoblastoma cell of origin Nat Rev Cancer 5 91-101 PMID: 15685194
14. Rudant J, Menegaux F and Lverger G (2007) Family history of cancer in children with acute leukemia, Hodgkin's lymphoma or non-Hodgkin's lymphoma: The ESCALE study (SFCE) Int J Cancer 121 1119-26 PMID: 17330239 doi:10.1002/ijc.22624

15. Mosse YP, Laudenslager M, Longo L, Cole KA, Wood A et al (2008) Identification of ALK as a major familial neuroblastoma predisposition gene Nature 455 930-5 PMID 18724359

16. Little J (1999) Epidemiology of Childhood Cancer (Lyons: IARC)

17. Maule MM, Zuccolo L, Magnani C et al (2006) Bayesian methods for early detection of changes in childhood cancer incidence: trends for acutelymphoblastic leukaemia are consistent with an infectious aetiology Eur J Cancer 421 78-83 PMID: 16324832 doi:10.1016/j.ejca.2005.07.028

18. Kinlen $L$ (2004) Infections and immune factors in cancer: the role of epidemiology Oncogene 23 634-8 PMID 15322509 doi:10.1038/sj.onc. 1207898

19. Murono S, Yoshizaki T, Sato H, Takeshita H, Furukawa M and Pagano JS (2000) Aspirin inhibits tumor cell invasiveness induced by Epstein-Barr virus latent membrane protein 1 through suppression of matrix metalloproteinase-9 expression Cancer Res 60 2555-61 PMID: 10811139

20. Speir E, Yu ZX, Ferrans VJ, Huang ES and Epstein SE (1998) Aspirin attenuates cytomegalovirus infectivity and gene expression medicated by cyclo-oxygenase 2 in coronary artery smooth muscle cells Circ Res 832 210-6 PMID: 9686761

21. Smith A, Roman E and Simpson J (2006) Childhood leukemia and socioeconomic status: fact or artefact? A report from the United Kingdom childhood cancer study (UKCCS) Int J Epidemiol 356 1504-13 PMID: 16945940 doi:10.1093/ije/dyl193

22. Lightfoot TJ and Roman E (2004) Causes of childhood leukaemia and lymphoma Toxicol Appl Pharmacol 1992 104-117 PMID: 15313583 doi:10.1016/j.taap.2003.12.032

23. McKinney PA, Raji OY, van Tongeren $M$ and Feltbower RG (2008) The UK childhood cancer study: maternal occupational exposures and childhood leukaemia and lymphoma Radiat Prot Dosimetry 1322 232-40 PMID: 18922820 doi:10.1093/rpd/ncn265

24. Wigle DT, Arbuckle TE, Walker M et al (2007) Environmental hazards, evidence for effects on child health J Toxicol Environ Health B Crit Rev 10 1-2 3-39 PMID: $\underline{18074303}$

25. Wigle DT, Arbuckle TE, Turner MC et al (2008) Epidemiological evidence of relationships between reproductive and childhood health outcomes and 
environmental contaminants $\mathrm{J}$ Toxicol Environ Health $B$ Crit Rev 11 5-6 373-517 PMID: 18470797

26. Kim YI (2007) Folic acid fortification and supplementationgood for some but not so good for others Nutr Rev 6511 504-11 PMID: 18038943 doi:10.1301/nr.2007.nov.504-511

27. French AE, Grant R, Weitzman S et al (2003) Folic acid food fortification is associated with a decline in neuroblastoma Clin Pharmacol Ther 74 288-94 PMID: 12966372 doi:10.1016/S0009-9236(03)00200-5

28. Bunin GR, Kuitjen RR, Buckley JD, Rorke LB and Meadows AT (1993) Relation between maternal diet and subsequent primitive neuroectodermal brain tumors in young children N Engl J Med 329 536-41 PMID: 8336753 doi:10.1056/NEJM199308193290804

29. Goh YI, Bollano E, Einarson TR and Koren G (2007) Prenatal multivitamin supplementation and rates of paediatric cancers: a meta-analysis Clin Pharmacol Ther 81 685-91 PMID: 17314929 doi:10.1038/sj.clpt.6100100

30. Schuz J, Weihkopf T and Kaatsch P (2007) Medication use during pregnancy and the risk of childhood cancer in the offspring Eur J Pediatr 166 433-41 PMID: 17345098 doi:10.1007/s00431-006-0401-z

31. Stallings VA (2008) Childhood cancer and vitamins: prevention and treatment Pediatr Blood Cancer 502 442-4 PMID: 18064638 doi:10.1002/pbc.21416

32. Craft AW (1998) Childhood cancer: improved prospects for survival but is prevention possible? Indian J Pediatr 656 797-804 PMID: 10773943 doi:10.1007/BF02831337

33. Glasgow JF (2006) Reye's syndrome: the case for a causal link with aspirin Drug Saf 2912 1111-21 PMID: 17147458 doi:10.2165/00002018-200629120-00003

34. Varner AE, Busse WW and Lemanske RJF (1998) Hypothesis: decreasing use of pediatric aspirin has contributed to the increasing prevalence of childhood asthma Ann Alergy Asthma Immunol 81 347-51 doi:10.1016/S1081-1206(10)63127-4

35. Johnsen JI, Lindskog M, Ponthan F, Pettersen I, Elfman L, Orrego A, Sveinbjornsson B and Kogner P (2004) Cyclooxygenase-2 is expressed in neuroblastoma, and nonsteroidal anti-inflammatory drugs induce apoptosis and inhibit tumor growth in vivo Cancer Res 64 7210-5 PMID: 15492235 doi:10.1158/0008-5472.CAN-04-1795

36. Ponthan $F$, Wickström $M$, Gleissman $H$, Fuskevag $O M$, Segerström L, Sveinbjörnsson B et al (2007) Celecoxib prevents neuroblastoma tumor development and potentiates the effect of chemotherapeutic drugs in vitro and in vivo Clin Cancer Res 131036 PMID: 17289900 doi:10.1158/1078-0432.CCR-06-1908

37. Baryawno N, Sveinbjörnsson B, Eksborg S, Orrego A, Segerström L, Oqvist CO et al (2008) Tumor-growth- promoting cyclooxygenase-2 prostaglandin E2 pathway provides medulloblastoma therapeutic targets Neuro Oncol 10 661-74 PMID: 18715952 doi:10.1215/15228517-2008$\underline{035}$

38. Blacklock CJ, Lawrence JR, Wiles D, Malcolm EA, Gibson $\mathrm{IH}$, Kelly CJ and Paterson JR (2001) Salicylic acid in the serum of subjects not taking aspirin. Comparison of salicylic acid concentrations in the serum of vegetarians, non-vegetarians, and patients taking low dose aspirin $\mathrm{J}$ Clin Pathol 547 553-5 PMID: 11429429 doi:10.1136/jcp.54.7. $\underline{553}$

39. Morgan G (2003) Should aspirin be used to counteract 'salicylate deficiency'? Pharmacol Toxicol 934 153-5 PMID: 14629738 doi:10.1034/j.1600-0773.2003.930401.x

40. Popkin BM (2006) Global nutrition dynamics: the world is shifting rapidly toward a diet linked with noncommunicable diseases Am J Clin Nutr 842 289-98 PMID: 16895874

41. Key TJ, Appleby PN, Spencer EA, Travis RC, Roddam AW and Allen NE (2009) Mortality in British vegetarians: results from the European Prospective Investigation into Cancer and Nutrition (EPIC-Oxford) Am J Clin Nutr 895 1613S1619S PMID: 19297458 doi:10.3945/ajen.2009.26736L

42. Smith MJ, Ford-Hutchinson AW, Walker JR and Slack JA (1979) Aspirin, salicylate and prostaglandins Inflammation Res 9 5-6 483-7 PMID 546171

43. Aronoff DM, Boutaud O, Marnett LJ and Oates JA (2003) Inhibition of prostaglandin $\mathrm{H} 2$ synthases by salicylate is dependent on the oxidative state of the enzymes $\mathrm{J}$ Pharmacol Exp Ther 3042 589-95 PMID: 12538810 doi:10.1124/jpet.102.042853

44. Weissmann G, Montesinos MC, Pillinger M, Cronstein BN (2002) Non-prostaglandin effects of aspirin III and salicylate:inhibition of integrin-dependent human neutrophil aggregation and inflammation in COX 2- and NF kappa B (P105)-knockout mice Adv Exp Med Biol 507 571-7 PMID: 12664642

45. Wang $Z$ and Brecher P (1999) Salicylate inhibition of extracellular signal-regulated kinases and inducible nitric oxide synthase Hypertension 341259 PMID: 10601128

46. Hinz B, Kraus V, Pahl A and Brune K (2000) Salicylate metabolites inhibit cyclooxygenase-2-dependent prostaglandin $E_{2}$ synthesis in murine macrophages Biochem Biophys Res Commun 2741 197-202 PMID: 10903918 doi:10.1006/bbrc.2000.3123

47. Higgs GA, Salmon JA, Henderson B and Vane JR (1987) Pharmacokinetics of aspirin and salicylate in relation to inhibition of arachidonate cyclooxygenase and antiinflammatory activity Proc Natl Acad Sci USA 845 1417-20 PMID: 3103135 doi:10.1073/pnas.84.5.1417 
48. Serhan CN, Yacoubian $S$ and Yang R (2008) Antiinflammatory and proresolving lipid mediators Annu Rev Pathol 3 279-312 PMID: 18233953 doi:10.1146/annurev. pathmechdis.3.121806.151409

49. Janakiram NB and Rao CV (2009) Role of lipoxins and resolvins as anti-inflammatory and proresolving mediators in colon cancer Curr Mol Med 9 565-79 PMID 19601807 $\underline{\text { doi: } 10.2174 / 156652409788488748}$

50. Johnsen JI, Lindskog M, Ponthan F, Pettersen I, Elfman L, Orrego A, Sveinbjörnsson B and Kogner P (2005) NSAIDs in neuroblastoma therapy Cancer Lett 228 195-201 PMID: 15975708 doi:10.1016/j.canlet.2005.01.058

51. Lau LM, Wolter JK, Lau JT, Cheng LS, Smith KM, Hansford LM, Zhang L, Baruchel S, Robinson F and Irwin MS (2009) Cyclooxygenase inhibitors differentially modulate p73 isoforms in neuroblastoma Oncogene 28 2024-33 PMID: $\underline{19363520}$ doi:10.1038/onc.2009.59

52. Lau L, Hansford LM, Cheng LS, Hang M, Baruchel S, Kaplan DR and Irwin MS (2007) Cyclooxygenase inhibitors modulate the p53/HDM2 pathway and enhance chemotherapy-induced apoptosis in neuroblastoma Oncogene 26 1920-31 PMID: 16983334 doi:10.1038/sj. onc. 1209981

53. Parashar B and Shafit-Zagardo B (2006) Inhibition of human neuroblastoma in SCID mice by low-dose of selective Cox-2 inhibitor nimesulide J Neurooncol 78 12934 PMID: 16552621 doi:10.1007/s11060-005-9079-8

54. Dickens DS and Cripe TP (2003) Effect of combined cyclooxygenase-2 and matrix metalloproteinase inhibition on human sarcoma xenografts $\mathrm{J}$ Pediatr Hematol Oncol 25 709-14 PMID: 12972806 doi:10.1097/00043426200309000-00007

55. Patti R, Gumired K, Reddanna P, Sutton LN, Phillips PC and Reddy CD (2002) Overexpression of cyclooxygenase-2 (COX-2) in human primitive neuroectodermal tumors: effect of celecoxib and rofecoxib Cancer Lett 180 13-21 PMID: 11911965 doi:10.1016/S0304-3835(02)00003-4

56. Kaneko M, Kaneko S and Suzuki K (2009) Prolonged lowdose administration of the cyclooxygenase-2 inhibitor celecoxib enhances the antitumor activity of irinotecan against neuroblastoma xenografts Cancer Sci 100 2193201 PMID 19673886

57. Kökoğlu E, Tüter Y, Sandikçi KS, Yazici Z, Ulakoğlu EZ, Sönmez H and Ozyurt E (1998) Prostaglandin E2 levels in human brain tumor tissues and arachidonic acid levels in the plasma membrane of human brain tumors Cancer Lett 132 17-21 PMID: 10397448 doi:10.1016/S0304-3835 (98)00127-X

58. Reynolds LM, Dalton CF and Reynolds GP (2001) Phospholipid fatty acids and neurotoxicity in human neuroblastoma SH-SY5Y cells Neurosci Lett 309 193-6 PMID: 11514074 doi:10.1016/S0304-3940(01)02071-7

59. Nathoo N, Barnett GH and Golubic M (2004) The eicosanoid cascade: possible role in gliomas and meningiomas J Clin Pathol 57 6-13 PMID: 14693827 doi:10.1136/jcp.57.1.6

60. Kökoğlu E, Tüter Y, Yazici Z, Sandikci KS, Sönmez H, Ulakoğlu EZ and Ozyurt E (1998) Profiles of the fatty acids in the plasma membrane of human brain tumors Cancer Biochem Biophys 16 301-12 PMID 9925279

61. Loh JK, Hwang SL, Lieu AS, Huang TY and Howng SL (2002) The alteration of prostaglandin E2 levels in patients with brain tumors before and after tumor removal $\mathrm{J}$ Neurooncol 57 147-50 PMID: 12125976 doi:10.1023/A: 1015782809966

62. Colllins E and Turner G (1975) Maternal effects of regular salicylate ingestion during pregnancy Lancet 2 335-8 PMID $\underline{51142}$ doi:10.1016/S0140-6736(75)92777-4

63. Coomarasamy A, Honest $\mathrm{H}$, Papaionnou S, Gee $\mathrm{H}$ and Khan KS (2003) Aspirin for the prevention of preeclampsia in women with historial risk factors: a systematic review Obstet Gynecol 101 1319-32

64. de Boo HA and Harding JE (2006) The developmental origins of adult disease (Barker) hypothesis Aust NZ J Obstet Gynaecol 46 1 4-14 PMID: 16441686 doi:10.1111/ $\mathrm{j} .1479-828 \times .2006 .00506 . \mathrm{x}$

65. Martin RM, Gunnell D, Owen CG and Smith GD (2005) Breast-feeding and childhood cancer: A systematic review with meta-analysis Int J Cancer 117 1020-31 PMID: 15986434 doi:10.1002/ijc. 21274

66. Maynard M, Gunnell D, Emmett P et al (2003) Fruits, vegetables, and antioxidants in childhood and risk of adult cancer: the Boyd Orr cohort J Epidemiol Community Health 57 218-25 PMID: 12594199 doi:10.1136/jech.57.3.218

67. Hammal DM, Bell CL, Craft AW and Parker L (2005) Second primary tumors in children and young adults in the north of England (1968-99) Pediatr Blood Cancer 452 155-61 PMID: 15880357 doi:10.1002/pbc.20448

68. Paterson JR, Baxter G, Dreyer JS, Halket JM, Flynn R and Lawrence JR (2008) Salicylic acid sans aspirin in animals and man: persistence in fasting and biosynthesis from benzoic acid J Agric Food Chem 5624 11648-52 PMID: 19053387 doi:10.1021/jf800974z

69. Healy E, Newell L, Howarth P and Friedmann PS (2008) Control of salicylate intolerance with fish oils $\mathrm{Br} \mathrm{J}$ Dermatol 1596 1368-9 PMID: 18795922 doi:10.1111/j.1365-2133. 2008.08830.x

70. Knijnenburg SL, Kremer LC, van den Bos C, Braam KI and Jaspers MW (2010) Health information needs of childhood 
cancer survivors and their family Pediatr Blood Cancer 54 123-7 PMID 19743299

71. Winter C, Muller C, Hoffman C, Boos J and Rosenbaum D (2010) Physical activity and childhood cancer Pediatr Blood Cancer 54 501-10 PMID 19743298

72. Aung L, Khyne T, Yeoh AE, Quah TC and Tan AM (2009) A report from the Singapore Childhood Cancer Survivor Study (SG-CCSS): a multi-institutional collaborative study on long-term survivors of childhood cancer, initial analysis reporting for the SG-CCSS Ann Acad Med Singapore 388 684-9 PMID: 19736571

73. Dama E, Maule MM, Mosso ML, Alessi D, Ghisleni M, Pivetta E, Pisani P, Magnani C, Pastore G and Merletti F (2009) Life after childhood cancer: marriage and offspring in adult long-term survivors-a population-based study in the Piedmont region, Italy Eur J Cancer Prev [Epub ahead of print] PMID: 19734794

74. Judge Santacroce S, Asmus K, Kaden-Lottick N and Grey M (2010) Feasibility and preliminary outcomes from a pilot study of coping skills training for adolescent-young adult survivors of childhood cancer and their parents $\mathrm{J}$ Pediatr Oncol Nurs 27 10-20 PMID 19687468

75. Faghahati S, Delaporte T, Toussoun G, Gleizal A, Morel F and Delay E (2010) Treatment by fat tissue transfer for radiation injury in childhood facial cancer Ann Chir Plast Esthet 55 169-78 PMID: 19679386

76. Chou LN and Hunter A (2009) Factors affecting quality of life in Taiwanese survivors of childhood cancer $J$ Adv Nurs 65 2131-41 PMID: 19674170

77. Jäger M, Zilkens C, Westhoff B, Jelinek EM, Kozina G and Krauspe R (2009) Efficiency of iloprost treatment for chemotherapy-associated osteonecrosis after childhood cancer Anticancer Res 298 3433-40 PMID: 19661369

78. Meacham LR, Sklar CA, Li S, Liu Q, Gimpel N, Yasui Y, Whitton JA, Stovall M, Robison LL and Oeffinger KC (2009) Diabetes mellitus in long-term survivors of childhood cancer. Increased risk associated with radiation therapy: a report for the childhood cancer survivor study Arch Intern
Med 16915 1381-8 PMID: 19667301 doi:10.1001/ archinternmed.2009.209

79. Reulen RC, Zeegers MP, Wallace WH, Frobisher C, Taylor AJ, Lancashire ER, Winter DL and Hawkins MM (2009) British Childhood Cancer Survivor Study. Pregnancy outcomes among adult survivors of childhood cancer in the British Childhood Cancer Survivor Study Cancer Epidemiol Biomarkers Prev $18 \quad 8 \quad 2239-47$ PMID: 19661083 doi:10.1158/1055-9965.EPI-09-0287

80. Laverdière C, Liu Q, Yasui Y, Nathan PC, Gurney JG, Stovall M et al (2009) Long-term outcomes in survivors of neuroblastoma: a report from the Childhood Cancer Survivor Study J Natl Cancer Inst 10116 1131-40 PMID: 19648511 doi:10.1093/jnci/djp230

81. Mulder RL, Kremer LC, Santen HM, Ket JL, Trotsenburg AS, Koning CC, Meeteren AY, Caron HN, Neggers SJ and Dalen EC (2009) Prevalence and risk factors of radiationinduced growth hormone deficiency in childhood cancer survivors: A systematic review Cancer Treat Rev 35 61632 PMID: 19640651

82. Chen TT, Rakheja D, Hung JY, Hornsby PJ, Tabaczewski P, Malogolowkin M, Feusner J, Miskevich F, Schultz R and Tomlinson GE (2009) Establishment and characterization of a cancer cell line derived from an aggressive childhood liver tumor Pediatr Blood Cancer 536 1040-7 PMID: 19637320 doi:10.1002/pbc. 22187

83. Nazemi KJ and Malempati S (2009) Emergency department presentation of childhood cancer Emerg Med Clin North Am 273 477-95 PMID: 19646649 doi:10.1016/ j.emc.2009.04.008

84. Harrington AD, Kimball TG and Bean RA (2009) Families and childhood cancer: an exploration of the observations of a pediatric oncology treatment team Fam Syst Health 271 16-27 PMID: 19630442 doi:10.1037/a0014909

85. Ozono S, Saeki T, Mantani T, Ogata A, Okamura H, Nakagawa SI, Ueda K, Inada H and Yamawaki S (2010) Psychological distress related to patterns of family functioning among Japanese childhood cancer survivors and their parents Psychooncology 19 54-52 PMID $\underline{19623675}$ 